\title{
The effect of Zinc, Tin, and Lead coating on corrosion protective effectiveness of steel reinforcement in concrete
}

\author{
Abdulkareem Mohammed Ali Alsamuraee ${ }^{1}$ and Hani Aziz Ameen ${ }^{2}$ \\ ${ }^{1}$ Ministry of Science \& Technology- Baghdad, Iraq, E-mail:samuraee2000@hotmail.com \\ 2 Technical College - Baghdad - Iraq, E-mail:haniazizameen@yahoo.com
}

\begin{abstract}
The research was aimed at developing new reinforcement materials by using of different coating materials, included zinc, tin and lead. The experimental works included examination of coating defect, coating Adhesion study, and the adhesion between concrete and coated bars, and different techniques are employed to assess the performance of the reinforcement embedded in concrete at a saline environment of $3.5 \% \mathrm{NaCl}$ solution. These include; Accelerated Corrosion Test ASTM G 109, Half Cell Potential Test ASTM C876, electrochemical polarization by Linear and Tafel polarization techniques, microstructure, and visual inspection. Some improvement to the ASTM G109 standard test method were suggested and led to get more useful results in a shorter period. The trend of the corrosion rate results of the all specimens (worst-to-best) can be arranged as follows:
\end{abstract}

Galvanized CRS > untreated CRS > tin coated CRS > lead coated CRS > SST316

Keywords: Corrosion, Steel reinforcement, Metal coating, ASTM G 109, Concrete.

\section{INTRODUCTION}

Under normal circumstances concrete provides a protective environment for steel reinforcement. Concrete is a hardened mixture of cement, aggregate, and water. The first important matter with respect to corrosion prevention is the $\mathrm{pH}$ of the concrete, or rather the $\mathrm{pH}$ of the pore solution in the concrete at the steel surface. A well- hydrated Portland cement can contain $15-30 \%$ calcium hydroxide by weight of the original cement. This hydroxide in conjunction with other species when dissolved in the pore water, presents an alkaline environment of $12-13 \mathrm{pH}$ around the steel. Hence in accordance with well-documented behavior of iron in an alkaline environment, a protective film of gamma ferric oxide ( $\mathrm{Fe} 2 \mathrm{O} 3$ ) is formed on the steel surface. As a result, the reinforcement now rests within the passivation zone of the familiar Pourbaix diagram (Vassie ,1985).This immunity from corrosion can be destroyed and steel in concrete was depassivate by carbon dioxide and or chloride salts (Wheat and Deshpande,2001). The presence of chloride ions (Cl-) can disrupt the passivation film, in this case the $\mathrm{pH}$ is unaffected, chloride contamination of the concrete matrix is the principal cause of corrosion (Broomfield,1997). The deteriorating infrastructure requires use of innovative protective methodologies, which are commonly subdivided into two categories.
First, protection is attained through methods that slow the initiation of corrosion, or lengthen the time it takes chlorides to reach the embedded steel reinforcement. The second includes methods that lengthen the active corrosion period, the time between initiation of corrosion and the end of service life (Clemena,2003). In summery, to extend the service life of reinforced concrete structures, the following methods may be used:

-Increasing the time to initiate corrosion by increasing the cover depth and reducing the construction tolerances on the placement of the reinforcing steel and/or reduce the rate of chloride diffusion through the cover concrete by using a low permeable concrete.

-Increasing the chloride corrosion threshold by using a corrosion inhibitor admixture which works at the steel surface.

-Decreasing the rate of corrosion of the steel in critically chloride contaminated concrete by using coated reinforcing steel.

-Using non-corroding reinforcing steel (Furman et al., 2003).

-A more effective method is the use of cathodic prevention and cathodic protection (Jolley ,2003) coating is considered for steel embedded in concrete 
when the structure is to be exposed to moderately or highly corrosive conditions. Coating in most cases serves as a means of isolating embedded steel from the surrounding environment. Thus an intact coating shields the steel from the various adverse conditions occurring at the concrete-steel interface which can cause corrosion of the steel and subsequent failure of the structure (ASTM C900-06, 2006) .

There are numerous considerations to be made in selecting an optimum coating system for steel reinforcement. First is the durability of the coating when exposed to the aggressive environment. Another important consideration is selection of a coating that can be easily applied in the field or when it is necessary to apply it at the plant. The coating should be able to withstand considerable abuse in transport. Another important aspect of the coating is the surface preparation requirement necessary to provide adequate bond to the steel and, hopefully, to the concrete. It is also processes; the coatings must withstand the bending process with regard both to stretching of the important that the coating not be brittle nor subject to flow under stress (Hamid, 2002). Metallic coatings for steel reinforcement fall into two categories sacrificial and noble or non-sacrificial. In general, metals with a more negative corrosion potential (less noble) than steel, such as zinc and cadmium, give sacrificial protection to the steel. If the coating is damaged, a galvanic couple is formed in which the coating is the anode. Noble coatings such as copper and nickel protect the steel only as long as the coating is unbroken, since any exposed steel is anodic to the coating. Even where steel is not exposed, macrocell corrosion of the coating may occur in concrete through a mechanism similar to the corrosion of uncoated steel. Nickel, cadmium, and zinc have all been shown to be capable of delaying, and in some case preventing, the corrosion of reinforcing steel in concrete, but only zinc-coated (galvanized) bars are commonly available (ASTM G109-07,2007). Results of the performance of galvanized bars have been conflicting, in some cases extending the time-to-cracking of laboratory specimens, in others reducing it, and some times giving mixed results. Marine studies and accelerated field studies have shown that galvanizing will delay the onset of delimitations and spells but will not prevent them. In general it appears that only a slight increase in life will be obtained in severe chloride environments. Coating of steel bars is one of these techniques, which is characterized by easy application and does not need any technical requirement over that of bare steel bars. However, research efforts were devoted so far on epoxynonmetallic coating and hot dip galvanizing (Clemena, 2003). Recent publications showed that the former is, in fact, deficient where as conflicting views were expressed on the effectiveness of the latter. Furthermore, data are scare on other types of metallic coatings, particularly nickel, chromium, white metals ( $\mathrm{Zn}, \mathrm{Sn}$ and $\mathrm{Pb}$ ) and completely absent on double layer small thickness metallic coatings. The research was aimed at developing new reinforcement materials and evaluate the degree of benefit derived from the use of five different coated steels, these include electroplating by zinc and tin also a hot-dip coating by zinc, tin and lead, compared with uncoated and stainless steel reinforcing bars.

\section{Experimental}

Samples Preparation: The deformed bars of a diameter of $13 \mathrm{~mm}$ were used in this research. The chemical composition of steel bars is shown in Table(1), and the mechanical properties listed in table(2).

Table 1 Chemical compositions of steel bar specimens

\begin{tabular}{|c|c|c|c|c|c|c|c|c|c|}
\hline Chemical compositions * $^{*}$ & $\mathrm{Cr}$ & $\mathrm{Mn}$ & $\mathrm{Si}$ & $\mathrm{P}$ & $\mathrm{S}$ & $\mathrm{Co}$ & $\mathrm{Ni}$ & $\mathrm{Cu}$ & $\mathrm{Mo}$ \\
\hline$\%$ & 0.91 & 0.5 & 0.04 & 0.03 & 0.07 & 0.13 & 0.03 & 0.2 & 0.06 \\
\hline
\end{tabular}

Table 2 Mechanical properties of steel bar

\begin{tabular}{|c|c|c|c|c|}
\hline$\Phi(\mathrm{mm})$ & $\mathrm{Y}\left(\mathrm{N} / \mathrm{mm}^{2}\right)$ Yield & Tensile $\left(\mathrm{N} / \mathrm{mm}^{2}\right)$ & $\%$ Elongation at break & Bending 180 \\
\hline 0.13 & 413 & 623 & 20 & pass \\
\hline
\end{tabular}


Am. J. Sci. Ind. Res., 2011, 2(1): 89-98

Table(3) shows the types of reinforcing bars that prepared in-house and used in the present work.

Table 3 Types of Reinforcing Bars.

\begin{tabular}{|c|l|l|}
\hline Reinforcing bar & \multicolumn{1}{|c|}{ Treatment } & \multicolumn{1}{c|}{ Notes } \\
\hline Type 1 & As received & From Iraqi markets \\
Type 2 & Stainless steel 316L & As rod \\
Type 3 & Zn coating (hot dip) & Pure Zn \\
Type 4 & Zn coating (electroplating) & Acid cyanide solution \\
Type 5 & Sn coating (hot dip) & Pure Sn \\
Type 6 & Sn coating (electroplating) & Acid solution \\
Type 7 & Pb coating (hot dip) & Pure Pb \\
\hline
\end{tabular}

The applied coating thickness statistically characterized using ultrasonic coat thickness gauge (non destructive coating thickness gauges type T8822 produced by Times Group Company) and optical microscope supplied with video camera type Nickon-ECLIPSE-ME600 for all types of application to measure metal substrates coating on steel and iron substrates each bar examined for thickness coat at 10 different points using ultrasonic coat thickness meter the average coat thinness are summarized in table(4). Using microscope supplied with video camera type Nickon-ECLIPSE-ME600, all specimens were observed to study the different plating layers obtained by the different plating processes and to check film coatings for homogeneity and free from defects that would adversely affect performance or appearance of coating.

Table 4 Coating Thickness of all types

\begin{tabular}{|c|c|c|}
\hline Bar type & Mean Thickness Coat $(\boldsymbol{\mu})$ & Standard Deviation \\
\hline Zn coating (hot dip) & 65 & $+/-30$ \\
\hline Zn coating (electroplating) & 35 & $+/-10$ \\
\hline Sn coating (hot dip) & 70 & $+/-20$ \\
\hline Sn coating (electroplating) & 38 & $+/-12$ \\
\hline Pb coating (hot dip) & 108 & $+/-25$ \\
\hline
\end{tabular}

Coating Adhesion Test: An adhesive is a substance capable to join the surface of two materials (which call adherents) together to produce a joint, with high strength, so that the adhesion as the state in which two surfaces are held together by interfacial force, which may consist of valance forces or interlocking action, or both. Many factors affected on adhesion, like surface preparation, surface tension, moisture and temperature. The interface between the filler and the adhesive materials could be important parameter to provide chemical and physical stable bond between them. Adhesion can be attributed to the five main mechanisms which can occur at the interface: Adsorption and wetting, electrostatic attraction, chemical bonding and, mechanical adhesion. A specialized testing method are required for the evaluation of the strength properties of the adhesive.
In this experimental part, tensile test was used to evaluate the force and strength between the coated layer $(\mathrm{Zn}, \mathrm{Pb}$, and $\mathrm{Sn})$ and the surface of the reinforcing bar. Two types of polymers were used as adhesive material, epoxy and PMMA. It was found that PMMA good adhesive material to evaluate the strength of coating films. PMMA powder (self cure acrylic) manufacture by Arma comp. and its hardener were used to preparation a thick layer out on the surface of the coating film. Kevlar fiber with diameter $1 \mathrm{~mm}$ and $100 \mathrm{~mm}$ length used as holder, The Kevlar fiber was immersed in a solution of PMMA and left 24 hours to cure. Instron Type (1122) with load cell range $0-500 \mathrm{~N}$ was used to record tensile force, the cross head speed was $0.5 \mathrm{~mm} / \mathrm{min}$, Fig.(1) shows the test set up. 
Am. J. Sci. Ind. Res., 2011, 2(1): 89-98

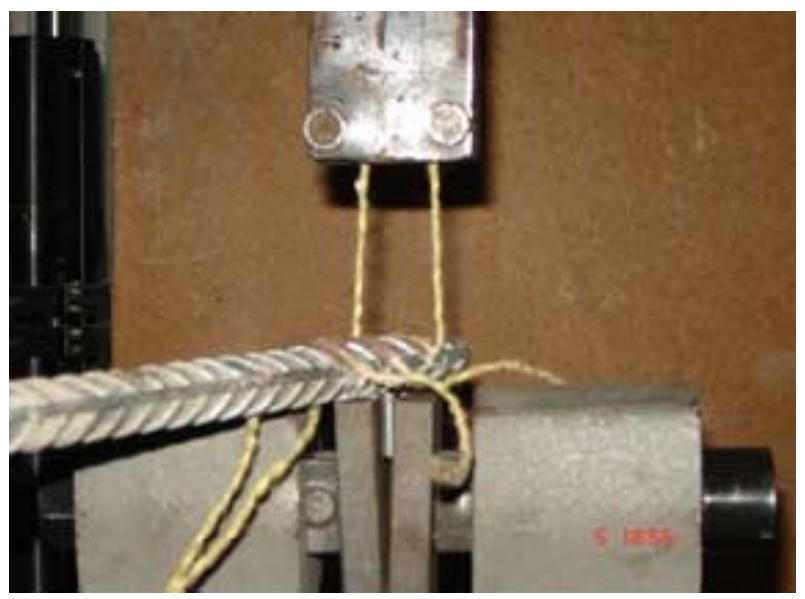

Fig.1 Pulling out Kevlar fiber

Pull-Out test: This test method covers determination of the pullout strength of hardened concrete by measuring the force required to pull an embedded metal insert and the attached concrete fragment from a concrete test specimen or structure. An experimental investigation was conducted to examine the bond strength characteristics of different types of steel rebar under monotonic loading. Tinius Olsen Hydraulic Tension Testing Machine, Hook-Bolt Testing Equipment consisting of hydraulic ram and pump and associated hardware load cell indicator with a minimum capacity of 36,000 pounds, apply a tensile load of 19,000 pounds to the rebar. The rebar shall withstand the applied load with zero slippage, slowly release the proof load and remove the test equipment in reverse order used for installation. The test set-up, load application, instrumentation and measurement, were fabricated. The specimen was new cylinder concrete mold with the reinforcing bar embedded in the middle. Additional pullout tests conducted using specimens previously used to evaluate the corrosion rate by rapid macrocell tests reported in the phase one of this study. The applied force recording was stopped when the maximum force reach a point at which the recorded displacement increased with decreasing force.

Accelerated Corrosion Test ASTM G109: Forty two bars $(400 * 13 \mathrm{~mm})$ of the 7 kinds of reinforcing bars listed in table(1), 6 bars for each type (duplicates) were drilled at one end $(6 \mathrm{~mm})$, each ends of the bars were taped with electroplater's tape so that a (200 $\mathrm{mm}$ ) portion in the middle of the bar was barred, then $100 \mathrm{~mm}$ length of plastic tubing were placed over the tape at each end of the bar. Each three bars from the same kind were placed in wooden mold of the dim $(300 * 150 * 150 \mathrm{~mm})$, one bar on top and two bars on the bottom, so there were 14 wooden molds for the 42 bars. The concrete mixture was made by mixing dry cement, sand \& aggregates then water added at a ratio of $60 \%$ by weight of the cement, in a mixing machine. The admixture was poured to the 14 wooden molds with the enhancement of stage vibrator then a crack is simulated parallel to and above the top reinforcing bar through the insertion of a $\left(14^{*} 10^{*} 0.3 \mathrm{~cm}\right)$ stainless steel shim in a depth of $2 \mathrm{~cm}$ in the middle top side when the specimen is fabricated. The shim is removed within 24 hours of placement, leaving a direct path for chlorides to the reinforcing steel. The green forms were removed from the wooden molds. Then a Plexiglas dams $\left(15^{\star} 7^{*} 7 \mathrm{~cm}\right)$ were placed on the partially dried concrete specimens and sealed using silicon caulk from the outside, then the four vertical sides of each specimens were sealed with epoxy sealer type (Master Seal 180 by Degussa UAE Connection shunts and $100 \Omega$ resistors were attached to the bars imbedded in the concrete specimens. The test procedure conducted as follows:

-The 14 specimens supported on a wooden thick sheet at the ends of each, Fig.(2), then $3.5 \% \mathrm{NaCl}$ solution placed in the plastic dams, the specimens were subjected to alternate wetting and drying using $3.5 \% \mathrm{NaCl}$, evaporating of the solution minimized by covering the dams with plywood, the wetting period lasted 10 days, followed by removing the solution allowing the specimens to dry at R.T for 10 days 
more than 20 days exposure was repeated continuously. Fresh $\mathrm{NaCl}$ was prepared at the beginning of each wet cycle, The top surface of the specimens was washed periodically with clean water.

-After 10 days, the voltage across the resistors was automatically recorded using high impendence voltmeters via data loggers, and measurements were continued for a period of 210 days.
-The corrosion current is determined by measuring the voltage drop across the resistor. then corrosion rate is determined by using Faraday's law. The corrosion potentials of the anode and the cathode are measured with respect to a saturated calomel electrode (SCE) after the circuit has been disconnected for at least two hours with DM-9680 INTELLEGENT MULTIMETER /Lurton Itd and data loggers type DL-9601A Which serves to save recorded data with real time periods .

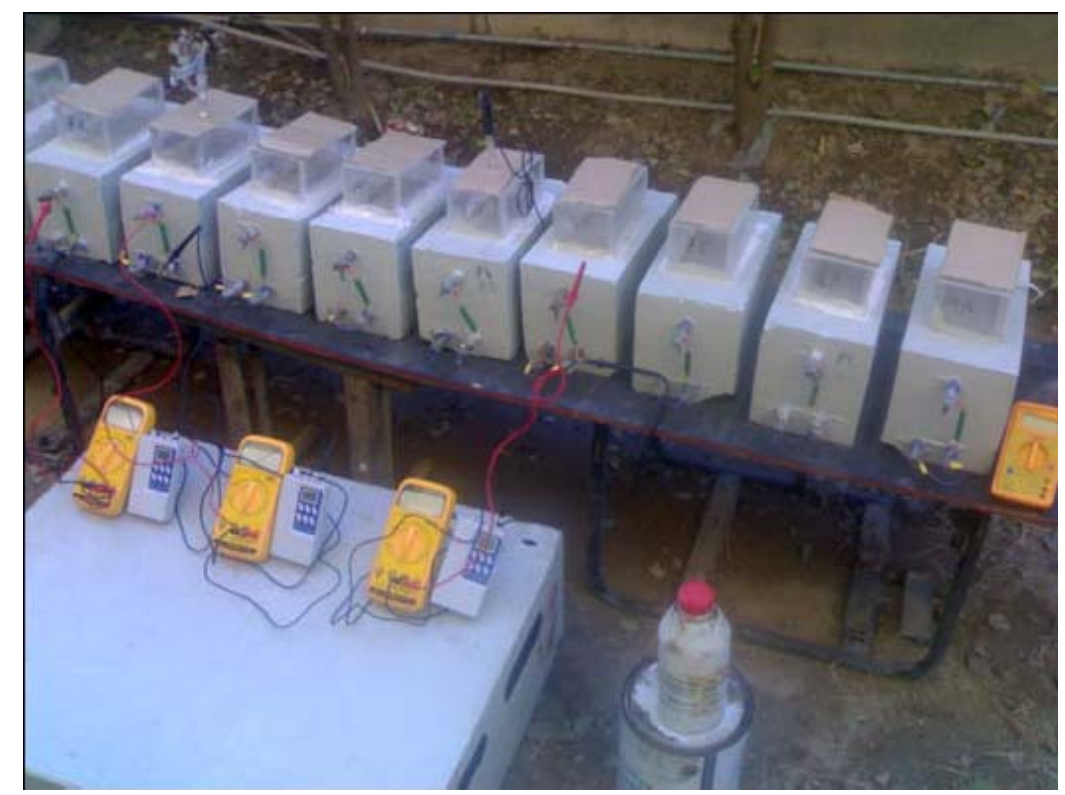

Fig.2 Improved ASTM G109 specimens set up

Immersion Test: Immersion tests, duplicate for each of the same seven bar types table (1), were conducted at room temperature using the conventional weight loss method reported in ASTM procedure ASTM-G-31-72 (ASTM G 31-72, 2004) and the ASTM G69-80 (ASTM G69-97,2003) standards where the surface finishing and cleaning of weight-loss measurements according to the ASTM G1 \& G-4 (ASTM G4,2008). Test bars had dimensions of approximately $13 \mathrm{~mm}$ dia. and $170 \mathrm{~mm}$ length with area of approximately $35 \mathrm{~cm} 2$. The specimens were degreased by washing in soap solution, followed by a Deionized (DI) water rinse, and then a high purity ethanol rinse before being air dried and weighed to an accuracy of three decimal places by electronic scale type SCALTEC SBA 41.Each test apparatus consisted of a 1,000-ml Pyrex container. The test specimens were immersed in the simulate concrete solution (saturated calcium hydroxide-pH 12.5)) with $3.5 \% \mathrm{NaCl}$ and taken out at 7 days intervals for testing up to a total of 120 days. At each time corrosion product formed on the corroded bars were removed by scrubbing the specimens with a brush. The tests required periodic additions of $D I$ water to maintain the liquid level. The cleaned specimens were dried thoroughly and reweighed. With the same electronic scale. The cleaning procedures were used before each weighing at each stage of the corrosion test. At the end of the testing period, the specimens were removed, washed in DI water and ethanol and then dried in air and photographed. Each specimen was visually examined for localized attack and a visual corrosion.

Tafel Extrapolation: Polarization resistance tests are used to obtain the microcell corrosion rates. In 
the tests, cell current readings are taken during a short, slow sweep of the potential. The sweep typically is from -100 to $+100 \mathrm{mV}$ relative to open circuit potential OCP. In this range, the current versus voltage curve is roughly linear. A linear fit of the data to a standard model gives an estimate of the polarization resistance, which used to calculate corrosion density Icorr. and corrosion rate. The tests are performed using a WENKING Mlab multi channels Potentiostat and SCI-Mlab corrosion measurement system from Bank EleketroniksIntelligent Controls $\mathrm{GmbH}$, Germany, 2007. In the tests two types of sample shape metal sheet and bar were used as the working electrode, a saturated calomel electrode immersed in salt solution is used as the reference electrode, and a platinum electrode is used as the counter electrode. The data file from a polarization resistance test is analyzed by the $\mathrm{SCl}$ data analysis package provided with the SCIMlab200.

\section{RESULTS AND DISCUSSION}

Optical microscopic images used to check film coatings for homogeneity and free from defects that would adversely affect performance or appearance of coating. They showed some times poor agreement with the ultrasonic coat measurements as shown in Fig.(3)
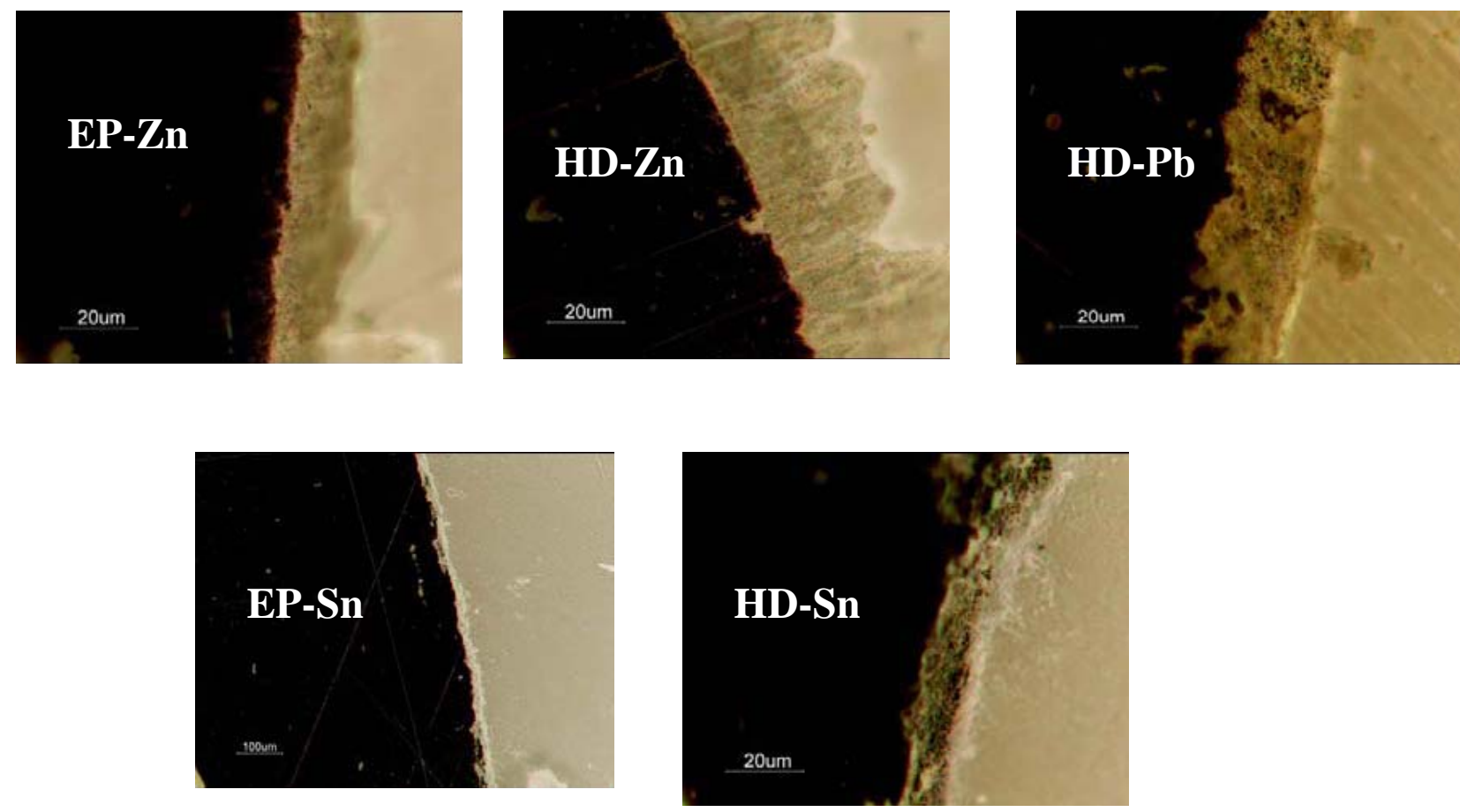

Fig.3 The microstructures of all coated bars

The adhesion strength tests between the surface of the un-coated reinforcing bar and PMMA was 0.27 $\mathrm{MPa}$ where all coated reinforcing bars showed adhesion strength range, between 0.47 to $0.57 \mathrm{MPa}$, and the photography for PMMA showed no coating material at the surface for adhesion Matter, that mean the coating films have good adhesion force on the surface of steel bar. The surface for coating films showed high roughness so that the adhesion strength will increased because of the mechanical interlock between the PMMA the surface. The compressive strength of the concrete specimens were measured and used to identify the bond force. The test results of the new concrete specimens (after 30 days), revealed that the bond strength between the steel bar and the strength concrete is high and similar each other. Bond pullout never occurred with the all coated bars. While the general shape of the stress-slip curves varied little, the bond stress magnitude didn't vary. The results of the improved Accelerated corrosion test ASTM G109 include the estimation of the corrosion potentials of the anode and cathode, The average corrosion potentials for the anode bars recorded are shown in Fig.(4). 
Am. J. Sci. Ind. Res., 2011, 2(1): 89-98

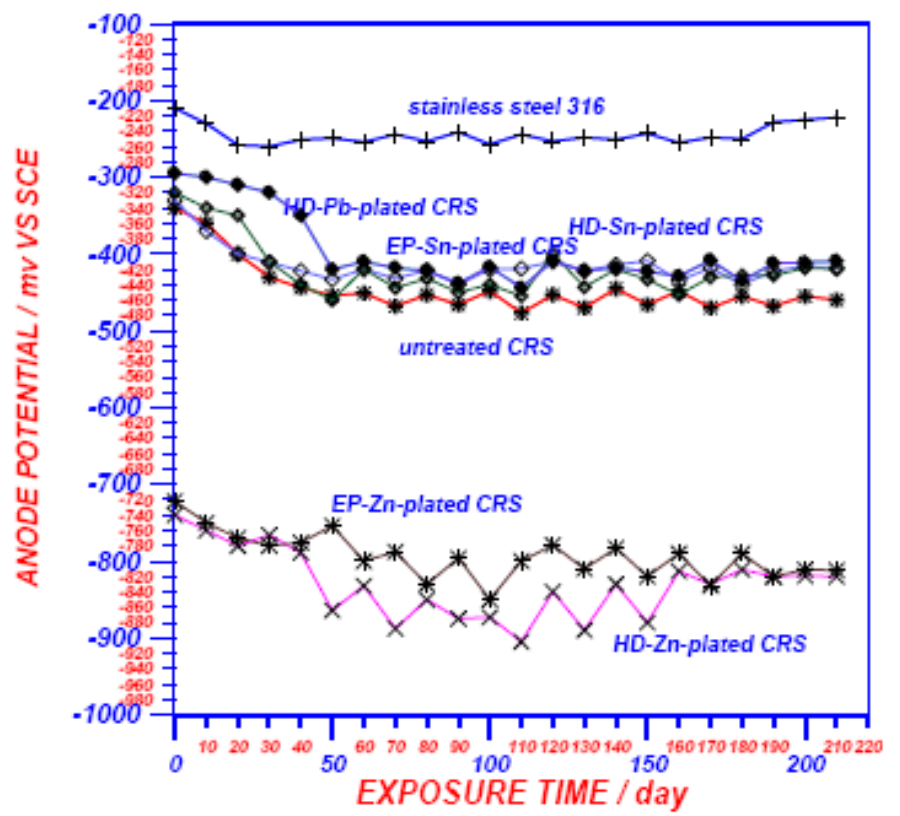

Fig.4 Anode potential vs. exposure time, ASTM G109

The corrosion potentials are measured with respect to a saturated calomel electrode (SCE), the voltage corrosion current density which calculated shown in across the 100 resistor where recorded and the Fig.(5).

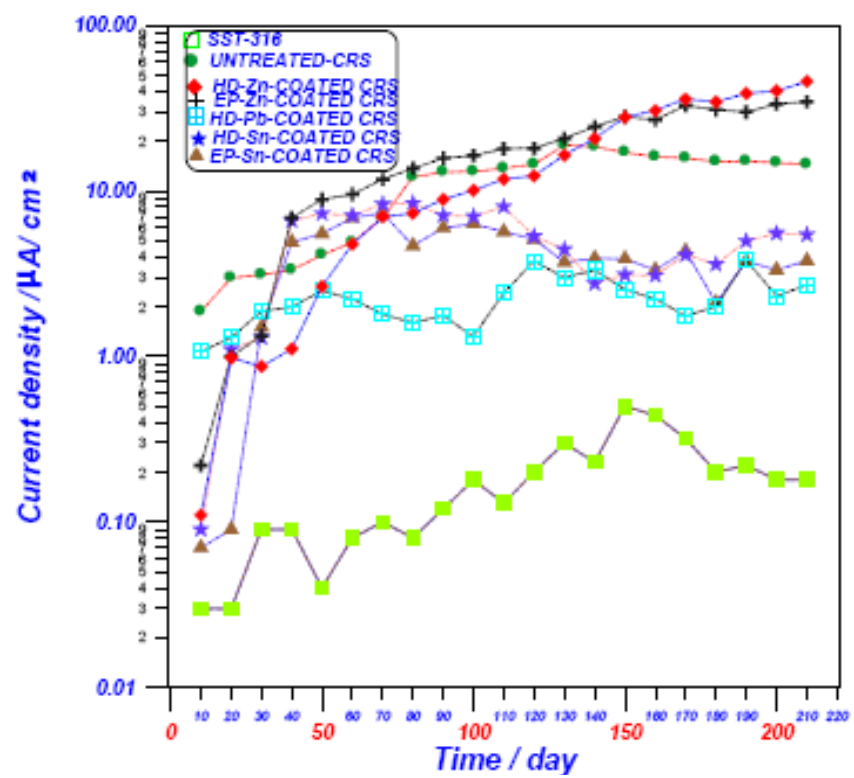

Fig. 5 Corrosion current density vs. exposure time, ASTM G109

From these figures and tables the following results can be estimated :
-SSt-316 is absolutely the best reinforcing bar and it behaved as noble alloy at the test conditions of ASTM G109.where CR didn't exceeded $0.3 \mathrm{mpy}$. 
-The two types of the galvanized bars showed more activity and corroded faster (around $20 \mathrm{mpy}$ ) than the untreated CRS (around $8 \mathrm{mpy}$ ),

-The lead showed very good corrosion resistance (3 mpy) in comparison with the untreated-CRS, the corrosion behavior appeared at the first 30 days and remains constant for the rest of exposure time.

-Electroplated tin and hot dip tin corroded very slowly (around $4 \mathrm{mpy}$ ) in comparison with untreated-CRS, and the two types of tin-coating showed negligible differences of the corrosion activity.

In general speaking using noble coating like lead or tin need to proceed perfectly, because defects of the coating layer on the surfaces of the reinforcing-CRS will lead to very fast point corrosion even than the untreated-CRS.

The weight loss $(\mathrm{WL})$ results and visual observations indicate that there is no corrosion problems associated with the SST316 at the environmental conditions studied in this test program, lead and tin coated CRS showed some degree of corrosion, the rates were around 10 and 15 mpy respectively and they lost their shinny appearance due to very thin tarnished layer formed on their surfaces. where untreated CRS and Zinc coated CRS bars undergoes with a much higher corrosion rates 20 and 30 mpy respectively, the visual examination photographs supported the trend of weight losses, red rust covered the untreated CRS and the test solution became brown in color after some days of starting immersion period, where Zn coated CRS covered with white smut. Galvanized CRS show high corrosion rates at the first 70 days ( $\geq 28 \mathrm{mpy}$ ) then falls down to values approach that of untreated CRS (18 mpy) or some times less which can be explained by fast formation of zinc hydroxide on the galvanized bar then when its quantities became as much as enough to cover all the surface of the bar, the corrosion rate became slower (ASTM G69-97,2003), where leaded CRS underwent contentious slower homogeneous corrosion (Fig.(6)) .

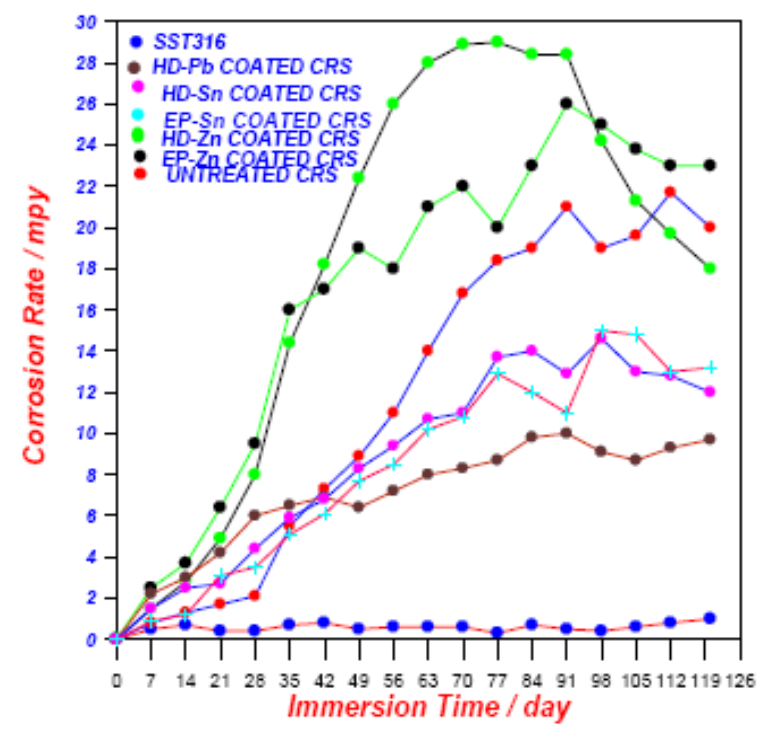

Fig.6 CR estimated from immersion tests at $\mathrm{R} . \mathrm{T}$ in saturated $\mathrm{Ca}(\mathrm{OH})_{2}$ with $3.5 \% \mathrm{NaCl}$ for 120 days

The corrosion rate were estimated from the plots of polarization curves and using Tafel extrapolation as described before as shown in Fig.(7). The results indicate that SST 316 to be the best performer and untreated CRS bar the worst. Corrosion rate for the other types are 3-30 times greater than for the solid 316 SS, small difference is apparent between the lead coated CRS bar and tin coated CRS bar, in 
general speaking the trend is similar to the two other methods, ASTM G109 test and immersion test (WL), but with higher values. Also, data for disk type for all specimens indicate relatively low variability, probably reflecting the cleaner, more uniform surface condition compared to the bar type that had an as received finish.

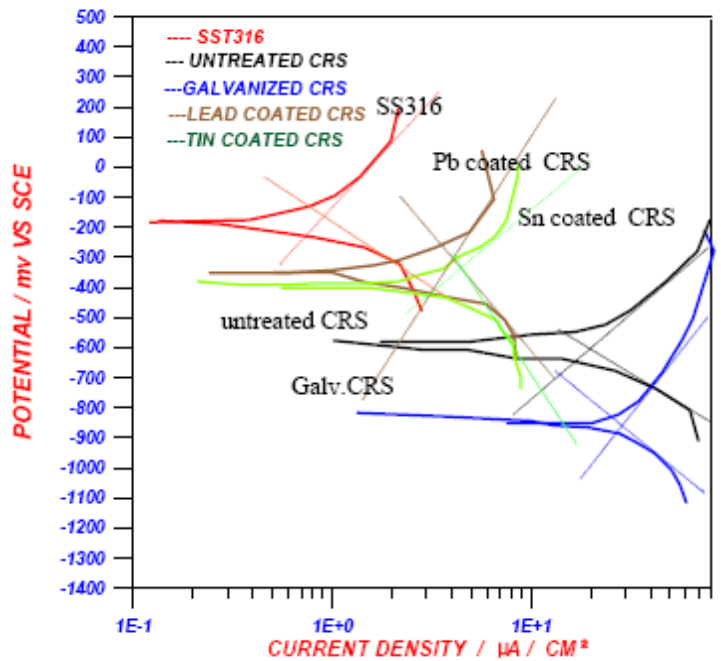

Fig.7 Polarization curve of specimens as labeled, in saturated $\mathrm{Ca}(\mathrm{OH})_{2}+3.5 \% \mathrm{NaCl}$.

\section{CONCLUSIONS}

1-The plating process of all types had no effect on the tensile properties of the base bar tensile strength around $621 \mathrm{MPa}$ with Max. Force around $19620 \mathrm{~N}$. 2-The pull-out test results revealed that the bond strength between the steel bar and the strength concrete is high and similar each other.

3-The suggested improving steps to the ASTM G109 procedure gave excellent results to reduces the test exposure time SSt-316 is absolutely the best reinforcing bar The two types of the galvanized bars showed more activity and corroded faster (around $20 \mathrm{mpy}$ ) than the untreated CRS (around 8mpy), The lead showed good corrosion resistance mpy) Electroplated tin and hot dip tin corroded very slowly (around $4 \mathrm{mpy}$ ).

4-Immersion test reveled no corrosion problems associated with the SST316 at the environmental conditions studied in this test program ,lead and tin coated CRS showed some degree of corrosion, the rates were around 10 and 15 mpy respectively and they lost their shinny appearance due to very thin tarnished layer formed on their surfaces. untreated CRS and Zinc coated CRS bars undergoes with a much higher corrosion rates 20 and 30 mpy respectively, and visual examination photographs supported the trend of weight losses.
5-The results of the LPR tests indicate that SST 316 to be the best performer and untreated CRS bar the worst, Corrosion rate for the other types are 3-30 times greater than for the solid 316 SS, small difference is apparent between the lead coated CRS bar and tin coated CRS bar, the trend is similar to the two other methods, ASTM G109 test and immersion test (WL), but with higher values. The corrosion rate for the untreated CRS bar increased with time, whereas that for the galvanized CRS bar decreased after reaching a limiting value, indicating a formation of stable and protective passive film, The performance ordering for the all specimens based upon the LPR data (worst-to-best) can be arranged as follows:

Galvanized CRS > untreated CRS > tin coated CRS , lead coated CRS, SST316.

6-The prices consideration showed acceptable values for all coatings with some higher costs for Tin coating but still more lower than SSt. bars.

7-Inspight of the hazardous effects of the lead metal it showed good corrosion performance and we believe in possibility to use it as a coating for reinforcing bar with taking in account the type of concrete structure to be constructed. 


\section{REFERENCES}

Vassie P. " Reinforcement Corrosion and the Durability of Concrete Bridge", Corrosion Prevention \& Control, June, PP.43-49. 1985.

Wheat H. G. and Deshpande P. G. "Alternative Reinforcement Materials for Concrete- A State of the Art Review", CORROSION, Paper 01652, 2001.

Broomfield J. " Corrosion of Steel in Concrete: Understanding, investigation on and Repair", 1st Ed. 1997.

Clemena G. " Testing of Selected Metallic Reinforcing Bars for Extending the Service Life of Future Concrete Bridge", VTRC 03-R7RB, June ,2003.

Furman Y., Kharshan M. and Chandler C.J. "Corrosion 2004 NACE", paper no. 04418, 2004

Jolley M. J. " Evaluation of Corrosion-Resistant Steel Reinforcement", Center of Transportation Research and Education, lowa State University,2003.

ASTM C900-06 Standard Test Method for Pullout Strength of Hardened Concrete, 2006.
Hamid H. H., "Corrosion Protection of Metallic Coated Steel Reinforcement in Concrete", Ph. D. Thesis, Military College for Engineering, 2002.

ASTM G109-07 "Standard Test Method for Determining Effects of Chemical Admixtures on Corrosion of Embedded Steel Reinforcement in Concrete Exposed to Chloride Environments", 2007.

Clemena G. "Testing of Selected Metallic Reinforcing Bars for Extending the Service Life of Future Concrete Bridge", VTRC 03-R7RB, June, 2003.

Fullston D. "Zinc Coating Thickness Effects on Hot Dip Galvanized Steel Corrosion Rates at a Severe Marine Site", Corrosion \& Materials, Vol. 29, 2004.

ASTM G 31-72, "Standard Practice for Laboratory Immersion Corrosion Testing of Metals", 2004.

ASTM G69-97 " Standard Test Method for Measurement of Corrosion Potentials of Aluminum Alloys", 2003.

ASTM G4 " Standard Guide for Conducting Corrosion Tests in Field Applications", 2008. 